\title{
Saint Joan
}

\section{BRETT FARMER}

CHULALONGKORN UNIVERSITY

\author{
David M. Halperin \\ How to be Gay \\ Harvard University Press, Cambridge, MA, 2012 \\ ISBN 9780674066793 \\ RRP US\$49.95
}

In blatant disregard of proverbial counsel, How to be Gay, the latest effort from David M. Halperin, Professor of the History and Theory of Sexuality at the University of Michigan, is a book that demands, dare one say screams, to be judged by its cover. Emblazoned with multiple images of a naked young man walking in side profile, his hands raised in flamboyant gesticulation, all cast in a 'shocking pink' hue that my Dulux colour chart puts somewhere between Oriental Fuchsia and Mademoiselle, it's a cover design that would be politely described as arresting or, with less diplomatic reserve, loud. Clocking in at a mammoth 550 pages the book asserts its presence in the visual field with brazen materiality, defying attempts to slip it discretely into a bag or blend it into the background business of a desk or bookshelf. Like an outrageous queen at a party whose drunken shrieks pierce the hum, it's a book that flaunts its gayness from the outset with eyebrow-raising shamelessness. 
Then there's the title. Based on an undergraduate class Halperin ran at his university that became the focus of a mini-moral panic when it was picked up by conservative media, as documented with humourous verve in the opening chapter, How to be Gay provokes with its paradoxical mix of plainspeak and ambiguity. At once a declarative statement and a tentative question, the title piques with varied interpretability that is further accentuated by the cover's typographic design where the first and last words are rendered in bold upper case sans serif, HOW GAY, while the middle couplet to be appears as a lower case faux cursive, making it seem like a typographic manipulation of the kind beloved by 1970s deconstructionists, a bracketed infinitive, to be or not to be, gay identity sous rature. How (to be) Gay: Is gay something one does or something one is; is there a way to be gay or conversely not be gay; is being gay subject to degrees of potency, legibility, success; and, even more scandalously, is being gay something one learns, acquires or is initiated into?

If this final provocation was what most fully raised the ire of the conservatives who wrote en masse to Halperin and his university-panicked by the prospect that gayness might not only assert a right to exist in a publicly funded educational institution but, as in their worst paranoid fantasies of recruitment, be cast as something acquisitive, cultivated, generative-it proves no less unsettling to certain orthodoxies within sexuality studies as well. As Halperin sees it, a good deal of what passes as sexuality studies in the academy has effectively come under the same thrall of normalising assimilationism as mainstream gay politics where, 'under the protective coloration of an axiomatic opposition to "essentialism"', (63) the abiding assumption is that homosexuality is nothing more or less than a sexual orientation, that lesbians and 'gay men are all individuals' about whom 'it is impossible to generalize' and who ultimately 'are not any different from normal people'. (60) The 'understandable reluctance to accept essentialist assumptions about lesbians and gay men has hardened into an automatic self-justifying dogmatism', he writes, 'a visceral impulse to preempt the merest acknowledgment or recognition of any cultural patterns or practices that might be distinctive to homosexuals'. (63) Halperin admits to subscribing to such a view for many years himself, insisting that 'being gay had absolutely nothing necessarily to do with anything at all besides gay sex', that it was first and foremost 'an erotic experience-not a matter of sensibility or cultural practice' (38) and eschewing anything that might suggest otherwise. Yet, 
here he is with a book that seeks actively to turn such assumptions on their head, arguing that 'there really is such a thing as gay male subjectivity'-'ways of being, ways of feeling, and ways of relating to the larger social world that are fundamental to male homosexuality and distinctive to gay men'-and, further, that 'gay men's cultural practices offer us a way of approaching it, getting hold of it, describing it, defining it and understanding it'. (66) So what happened to effect such a radical reversal in Halperin's perspective? Well, in a nutshell, it seems he discovered Joan Crawford.

Belatedly introduced in middle age to what he calls 'the American gay curriculum' (56) - an eclectic catalogue of cultural objects and forms, from classic Hollywood movies and stars to Broadway musicals, disco and opera, that have been canonised by urban American gay subcultures and marshalled as the basis for distinctive gay taste economies-Halperin came to realise not only the pleasures of traditional gay culture but the productive role it plays in fostering and transmitting 'gay acculturation'. Unlike other minoritarian identities, most queer subjects grow into gayness in relative isolation, without the benefit of family, community and/or other institutional support structures to teach them 'how to be gay' and so 'they must discover their roots through contact with the larger society and the larger world'. (7) It's a process of queer socialisation that assumes overt form in young adulthood when entrance into gay communitarian social life is typically accompanied by various forms of initiatory acculturation-learning the lexicon of gay subcultural capital from ABBA to 'Liza with a Z'-but that frequently begins much earlier. Indeed, a good deal of Halperin's interest lies in the kind of queer acculturation that evolves in childhood wherein 'gay or proto-gay subjects' and even 'certain heterosexual subjects, who will later discover in themselves a deep affinity with gay culture, sometimes experience a strong and unerring attraction to its cultural forms from an early age, without being aware of such an attraction, at least not under that description'. (347) Moreover, as the combined reference to children and heterosexuals would suggest, the pith and core of this initiatory gayness is not so much sexual as aesthetic, a 'queer way of feeling' that is expressed through 'a peculiar, dissident way of relating to cultural objects ... and cultural forms'. As a cultural practice, Halperin asserts, 'male homosexuality involves a characteristic way of receiving, reinterpreting, and reusing mainstream culture, of decoding and 
recoding the heterosexual and heteronormative meanings already encoded in that culture, so that they come to function as vehicles of gay or queer meaning'. (12)

If these arguments about non-normative modes of gay decoding are not especially novel-indeed, the 'queering' of popular media has become a veritable subgenre of cultural studies-Halperin develops them in interesting directions. Of particular note is the book's central emphasis on approaching gay culture as a set or field of discursive practices rather than as expressions of individuals, gay culture as genre not psychology. Halperin is of course nothing if not a good Foucauldian and here he continues his longstanding theoretical project of developing a reading of 'sexual subjectivity without psychology', a fully social analysis of 'the inner life of homosexuality' without recourse to individualising or normalising theories of psychic constitution. (15) To this end he roots How to be Gay in a rigorously formalist methodology of descriptive poetics, apprehending gay culture as a particular kind of conventionalised discourse and emphasising the pragmatics and positivity of gay cultural 'forms as things in their own right'. (138) Only by pursuing an inductive approach that starts with the phenomena of gay culture, that reads them closely and responds to the particularity of their formal properties rather than, as is customary, starting with a theoretical frame into which that phenomena is cast, can we hope to arrive at a systematic apprehension of gay culture that remains at once attentive to its specificities and open to its indeterminate pluralism.

It's an approach that Halperin takes to literal heart, devoting the lion's share of the book's middle sections to an exhaustive, multi-layered case study of one very narrowly circumscribed object from the canon of traditional gay culture, a single figure in a single scene in a single movie: Joan Crawford in the climactic motherdaughter confrontation scene from Mildred Pierce (1945). Returning again and again to this iconic moment from a sudsy, albeit classic, Hollywood melodrama, beloved and fetishised by several generations now of gay subcultural reception, Halperin rehearses the same kind of defiantly anti-normative interpretive procedures central to gay decodings, seizing upon certain textual styles, images and attitudes in order to realise their figural potential for queer signification and empowering affect. The various themes and issues thrown up by Halperin's wilfully obsessive, creative readings of Mildred Pierce may not be entirely untrodden-indeed, for the most part, they revisit a broadly familiar tropology of gay cultural discourse from diva worship 
and gay male femininity through aestheticism, irony and camp to obsession with the mother-but the originality lies both in the devil of their extraordinarily observant detail and in their attention to 'the sexual politics of cultural form'. (260) To cite just one example, taking the generic profile of Mildred Pierce as melodrama at serious face value, Halperin develops a stunningly incisive account of how the film's melodramatic spectacle of histrionic extravagance and stylistic excess articulates a distinctive blend of intense emotionalism, enraged powerlessness and expressive defiance that has profound gay appeal and dissident capacity. Debarred from the straight male seriousness and dignity of tragedy, gay culture 'deliberately embraces melodrama as a pragmatic genre', (283) revelling in its histrionic inauthenticity and the disruptive strategies it allows for defusing social and sexual power relations. The 'political uses of Joan Crawford, and of woman's melodrama more generally, by gay men', Halperin asserts, work 'to forge an ironic perspective on scenes of compulsory, socially validated and enforced performance, to decommission supposedly authentic social identities and return them to their status as willfully or witlessly iterated roles'. (297)

In keeping with his model of inductive poetics, Halperin resists positing the dissident dynamics he identifies in Joan Crawford and Mildred Pierce as generalisable features of a universal gay culture tout court. Had he seized upon a different figure, text or form of gay subcultural reception, 'the resultant interpretation of gay male culture', he opines, 'might well lead to some very different conclusions'. (405) There would, most likely, be certain points of homology and overlap but there would also be important distinctions, pointing analysis in divergent directions and leading to a different picture of gay male subjectivity. Those differences, he asserts, are what precisely confirm the value of his conceptual model of locating gay culture in, and reading it through, 'the sexual politics of cultural form, the meaning of style, [and] the far-reaching aesthetic, gendered and sexual consequences of formal or stylistic differences'. (407)

How to be Gay is a provocative book in the best sense of the term in that it seeks to make a calculated intervention into existing debates around gayness and cultural identity, challenging comfortable verities and inspiring new or expanded ways of framing the discussion. I'm possibly not as convinced as Halperin seems to be that his book is breaking entirely new ground. He frequently resorts to a slightly 
awkward 'mock heroic' rhetorical posture, protesting that he's actually quite 'bad at being gay' and that 'there are plenty of gay men ... deeply versed in gay male culture ... who really ought to ... be writing this book', before adding with a world-weary sigh that because 'they're not doing this work themselves ... I'm going to have to do the explaining'. (36-7) It's simply not true to claim as Halperin does on several occasions that almost no one 'has performed a formal critique of a gay male cultural object or been interested in reading mass culture from the point of view of the gay male subject who is the consumer of it'. (125) Going no further than Halperin's own primary analytic terrain of diva worship, there are any number of critical studies that read gay diva worship and its texts with a central attention to formal properties of style from the pioneering work of Richard Dyer, which does at least get a brief mention, to the extensive critical oeuvres of Alexander Doty and Wayne Koestenbaum which don't, to say nothing of numerous articles and book chapters devoted to detailed readings of individual gay icons.

The book is also hampered by a rather dim view of contemporary gay culture, fuelled in large part by inadequate attention to the complexities of new sociocultural conditions. Despite proclaiming repeatedly that gay male culture 'turns out to have changed a lot less over time than we like to claim' and that gay men today 'have not stopped finding gay meaning in female icons, from The Golden Girls to Desperate Housewives to Lady Gaga', (349) Halperin gives contemporary gay culture, even contemporary formations of traditional gay culture, frustratingly short shrift. He's positively fuddy-duddy when it comes to digital cultures, accusing the internet of 'the destruction of the non-virtual gay commercial infrastructure' and turning gay life into 'a paradise for agoraphobes'. (439) Had he bothered to consider the manifold forms of online communication beyond the gay social networking sites and smartphone apps he seems to abhor-and even these are arguably more nuanced and enabling than the dismissive caricatures presented by Halperin-he'd possibly have discovered a vital scene of active queer cultural discursivity where young queers and/or queer-responsive people are producing precisely the kind of dissident figural queer reworkings of mainstream culture championed by Halperin, sometimes even using the same texts. Note to David, check out Techno Mildred Pearce or Joan Crawford Club Mix on YouTube; I think you'll like them. 
These are ultimately minor quibbles, however, and they certainly don't diminish the significance of Halperin's remarkable achievement with How to be Gay. It is a major new contribution to queer cultural studies that bristles with intelligence and insight, wrapped in Halperin's elegant and oft-times hilariously witty prose. You may not always agree with every aspect of his argument but you'll surely appreciate its intellectual vim and political value, and possibly never quite watch a Joan Crawford film in the same way again.

Brett Farmer is a lecturer in the Faculty of Arts, Chulalongkorn University, Bangkok. 